\title{
QUADROTORS IN THE PRESENT ERA: A REVIEW
}

\author{
Ritika Thusoo ${ }^{1}$, Sheilza Jain ${ }^{2}$, Sakshi Bangia ${ }^{3}$ \\ ${ }^{1}$ Research Scholar, ${ }^{2,3}$ Assistant Professor \\ 1, 2, 3 J.C. Bose University of Science \& Technology, YMCA, Faridabad, India \\ ritikathusoo@gmail.com, ${ }^{2}$ sheilzajain@gmail.com, ${ }^{3}$ sakshibangia@gmail.com
}

\begin{abstract}
The advancement in the field of aerial robotics and control engineering has created many opportunities for the utilization of Unmanned Aerial Vehicles (UAVs). Applications of UAVs from precision agriculture to delivering medicines and products at our doorsteps cannot be ignored. Quadrotors are the widely studied as subcategory of the rotor-type UAVs. Their ability to hover, vertical take-off and landing along with their small size and simple design make them suitable for many real-life applications like medicine delivery in containment zones struck with COVID-19. But under actuation caused due to four rotors to control six inputs creates instability in their flight. In this paper, Quadrotors and various Quadrotor applications are discussed. The various modeling and control techniques are discussed. Controlling techniques like LQR, LQG, PID and robust control is implemented for position, attitude and altitude control. Results for Proportional Integral and Derivative (PID) and Model Reference Adaptive Control (MRAC) of model generated using force-moment mathematical model are analyzed and compared using MATLAB Simulink. These control techniques are implemented for position, attitude and altitude control. In this paper, it has been concluded that MRAC performs better as compared to PID controller for position, attitude and Altitude control of Quadrotor.
\end{abstract}

Keyword: UAV, Quadrotors, Modeling, control techniques, flight controllers.

\section{Introduction}

Unmanned Aerial Vehicle (UAV)

Autonomous vehicles will take over the road, sky, and water transportation systems in the near future. The autonomous vehicles like drones or UAVs are aerial robots which have been associated with defense applications in the past. The advancement in sensor technology and communication techniques have made it possible to use UAVs for civilian tasks, like transportation of medicines, packages, and other goods in containment zones in COVID-19 struck area; establishing communication connections in disaster-struck areas, precision agriculture and surveillance activities. The UAVs fly without any pilot onboard. The level of autonomy of a UAV varies based on its application. UAVs can be used in inaccessible terrains adjoing country border. In an event of a gas leak or a chemical leak at a nuclear power station, the inspection of the area by human being is life-threatening and can be easily done by the UAVs.

The UAVs have innumerable opportunities to make human lives better by playing a vital role in the realization of Smart Cities. UAVs can be used for data collection, remote analysis and quick action implementation in the future smart cities.

This paper is a review of rotor-type UAVs i.e., a Quadrotor system. In section 1 , the introduction to UAVs is given. Detailed study of Quadrotor, its applications and control using PID and MRAC control is done in section 2. Results and discussion are discussed in section 3. Section 4 gives the conclusion of this paper.

Market Analysis of UAV

UAVs are controlled remotely having varied levels of autonomy and control based on its use in real-life applications[1]. This is a boon in areas inaccessible to human beings and during natural calamities [2]. With the ubiquitous use of UAVs, its market value is expected to increase manifolds. According to a report by Frost \& Sullivan, the net market value of the UAVs was $\$ 42.4$ billion from year 1998 to 2008[3] with the Compound annual growth rate (CAGR) of $12.2 \%$. Whereas according to a report published by $\mathrm{PwC}$ (PricewaterhouseCoopers), the net market worth of UAVs will be $\$ 127$ billion in 2027 with CAGR of $25.4 \%$ [4]. Figure 1, shows the expected trends in the net worth of the UAVs in the market. The data shown in the figure 1 is analyzed for the following countries: US, China, European Union and the rest of the world (Japan, Korea, India and South-east Asia)[5]. 


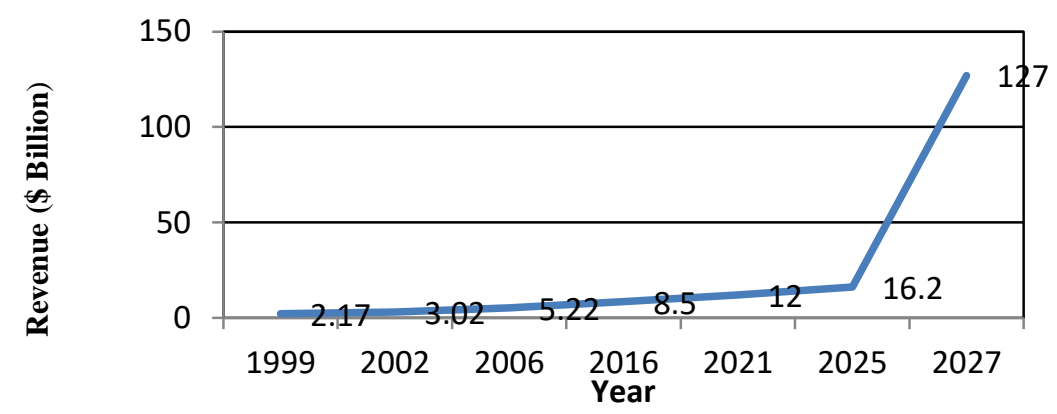

Figure 1. Net worth of UAVs in the market and its expected trends over the years[6]

BCG, a consulting firm evaluated the market trends and predicts that the UAVs used in the industry in the USA and Europe will be worth $\$ 50$ billion in the year 2050[7]. Figure 2, shows the percentage of the estimated revenue generated through major UAV based industries by the year 2027. It is estimated that the total revenue generated by UAV based agriculture industry will generate \$45.2 Billion whereas UAV based product delivery industry will generate $\$ 29.6$ billion. UAV based Transport industry, security, and surveillance and telecommunication sector will generate $\$ 13$ billion, $\$ 10$ billion and 6.3 billion dollars respectively.

\section{Estimated revenue by year 2027 (percentage)}

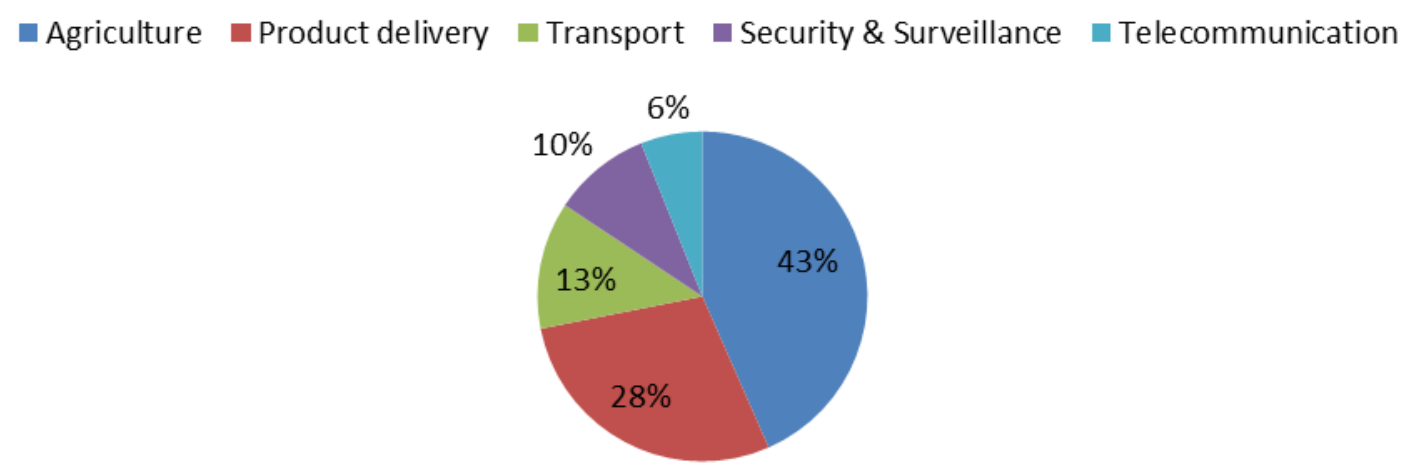

Figure 2. Pie chart showing the estimated revenue generated by major UAV based sector in percentage

\section{Different types of UAVs}

UAVs can be categorized based on their size, weight (mass), their flight time, height at which they can fly and the type of their wings. They can also be categorized based on their operating platform, i.e., the altitude at which they communicate with the base station. The UAVs are categorized based on so many factors because every UAV has a different applicability. Table 1, consolidates different types of UAVs based on altitude of operation, weight, fuel type, maximum altitude, deployment time, payload, endurance, heavier than air/ lighter than air and their wing type.

Table 1, Parametric analysis of different types of UAVs based on altitude of operation, weight, fuel type, maximum altitude, deployment time, payload, endurance, heavier than air/ lighter than air and their wing type.

\begin{tabular}{|c|c|c|c|c|c|c|c|c|c|}
\hline UAV type & $\begin{array}{l}\text { Low } \\
\text { Altitude } \\
\text { Platform } \\
\text { (LAP)/Hig } \\
\text { h Altitude } \\
\text { Platform } \\
\text { (HAP) }\end{array}$ & Weight & Fuel & $\begin{array}{l}\text { Maximum } \\
\text { Altitude }\end{array}$ & $\begin{array}{l}\text { Deployment } \\
\text { Time }\end{array}$ & Payload & Endurance & $\begin{array}{l}\text { Heavier than } \\
\text { Air } \\
\text { (HTA)/Light } \\
\text { er than Air } \\
\text { (LTA) }\end{array}$ & $\begin{array}{l}\text { Wing } \\
\text { type }\end{array}$ \\
\hline
\end{tabular}




\begin{tabular}{|c|c|c|c|c|c|c|c|c|c|}
\hline Quadrotor & LAP & Few kg's & $\begin{array}{l}\text { i)LiPo } \\
\text { battery } \\
\text { ii)Solar } \\
\text { cells }\end{array}$ & Upto $4 \mathrm{~km}$ & $\begin{array}{l}\text { Vertical } \\
\text { Take-off and } \\
\text { Landing }\end{array}$ & $\begin{array}{l}\text { Few } \\
\text { Kg's }\end{array}$ & Few hours & HTA & $\begin{array}{l}\text { Rotor } \\
\text { type } \\
\text { wing }\end{array}$ \\
\hline $\begin{array}{l}\text { Fixed Wing } \\
\text { UAV }\end{array}$ & LAP & Tens of kg's & $\begin{array}{l}\text { Fuel } \\
\text { Injection } \\
\text { Engine }\end{array}$ & Upto $5 \mathrm{~km}$ & $\begin{array}{l}\text { Launched by } \\
\text { catapult }\end{array}$ & $\begin{array}{l}\text { Few } \\
\text { Kg's }\end{array}$ & Few hours & HTA & $\begin{array}{l}\text { Fixed- } \\
\text { wing }\end{array}$ \\
\hline $\begin{array}{l}\text { Balloon } \\
\text { (Tethered } \\
\text { Helikite ) }\end{array}$ & LAP & Tens of kg's & Helium & $1.5 \mathrm{~km}$ & $\begin{array}{lr}\text { Easy } & \text { to } \\
\text { Deploy } & \text { and } \\
\text { takes } & 10-30 \\
\text { min }\end{array}$ & $\begin{array}{l}\text { Tens of } \\
\mathrm{kg} \text { 's }\end{array}$ & $\begin{array}{l}\text { From } 1 \text { day } \\
\text { to few days }\end{array}$ & LTA & - \\
\hline $\begin{array}{l}\text { Balloon(Proj } \\
\text { ect Loon- } \\
\text { Google) }\end{array}$ & HAP & Tens of kg's & $\begin{array}{l}\text { i)Helium } \\
\text { Balloon } \\
\text { ii)Solar } \\
\text { panels }\end{array}$ & $17-23 \mathrm{~km}$ & $\begin{array}{l}\text { Custom-built } \\
\text { auto } \\
\text { launchers }\end{array}$ & $\begin{array}{l}\text { Tens of } \\
\mathrm{kg} \text { 's }\end{array}$ & $\begin{array}{l}\text { Long } \\
\text { endurance } \\
\text { upto } 100 \\
\text { days }\end{array}$ & LTA & - \\
\hline Aircraft & HAP & $\begin{array}{l}\text { Few } \\
\text { thousand } \\
\text { kg's }\end{array}$ & $\begin{array}{l}\text { i)JP-8 jet } \\
\text { fuel } \\
\text { ii)Solar } \\
\text { panels }\end{array}$ & $15-20 \mathrm{~km}$ & Runway & $\begin{array}{l}\text { Upto } \\
1700 \mathrm{~kg}\end{array}$ & $\begin{array}{l}\text { i) } 15-30 \text { hour } \\
\text { (JP-8 jet) } \\
\text { ii)More than } \\
7 \text { days(Solar } \\
\text { panels) }\end{array}$ & HTA & $\begin{array}{l}\text { Fixed } \\
\text { Wing }\end{array}$ \\
\hline
\end{tabular}

Table 2. Different types of Unmanned Aerial Vehicles available in the market.

1 . Quadrotor/Quadcopter

e.g. Dragan Flyer X4-ES, Dragan Flyer X8, DJI Phantom, DJI Mavic Air, GoPro Karma Drone, Yuneec Typhoon Q500 4K, DJI Mavic 2 Pro, DJI Inspire 1 Pro, DJI Phantom 4 Pro, Mesicopter, STARMAC

2. Helicopter e.g. Yamaha RMAX

3. Hexacopter e.g. STARMAC, MJX X600, FQ777 126C Spider, Tarot 680 Pro

4. Octacopter e.g. Tarot X8, DJI S100 Spread Wings, xFold SPY X8

5. Fixed-wing e.g. Penguin C, DATAhawk, Q200

6. Flapping wing e.g. Robo Raven V, BATMAV, Nano Hummingbird

7. Blimp e.g. ZCH M1/11 and $\mathrm{YC}_{23}$ by EOMST, Mothership Aeronautics's solar-powered Blimp

8. Balloon

\section{Detailed study of Quadrotors}

Quadrotors is a subcategory of rotor-type UAV. The ease in their deployment, capability to hover at one place and low cost of making and maintenance makes them ideal for research work and use in real-time applications. It has four rotors that generate enough thrust to lift the Quadrotor from the ground.
A variation in the rotor's speed is used to design the vehicle's control system. The structural design of the Quadrotor is simple but since it is a multivariable system, the system has non-linear dynamics and is underactuated[8].

The four rotors of a Quadrotor are attached to its frame which can either be assembled in ' $X$ ' configuration or ' + ' configuration. The ' $\mathrm{X}$ ' configuration is preferred because this configuration allows all the rotors to contribute to the throttle 
that is required to overcome the earth's gravity and thus allows the Quadrotor to fly. There are four basic movements of a Quadrotor. One is translation motion along $\mathrm{x}, \mathrm{y}$ and $\mathrm{z}$-axis in 3D space and three rotational motions that are roll $\left({ }^{\varphi}\right.$-phi), pitch ${ }^{\theta}$-theta) and yaw motion $\left({ }^{\psi}\right.$-psi). The amalgam of these four movements allows a Quadrotor to traverse from one point to another. Figure 3, shows the ' $X$ ' configuration schematic diagram of a Quadrotor. The Quadrotors have rotors divided into two pairs $(1,3)$ and $(2,4)$ as shown in figure 4. The rotors $(1,3)$ have clockwise rotation and rotors $(2,4)$ have anti-clockwise rotation. There are two coordinate frames [9] associated with any rigid body[10]: one is the earth inertial frame (E-frame) and the other is the body-fixed frame of the vehicle (B-frame)[10]. The body-fixed frame is assumed to be attached to the quadrotor's body and it is also assumed that the Quadrotor frame is symmetric. This schematic design is followed by almost all the researchers across the world.

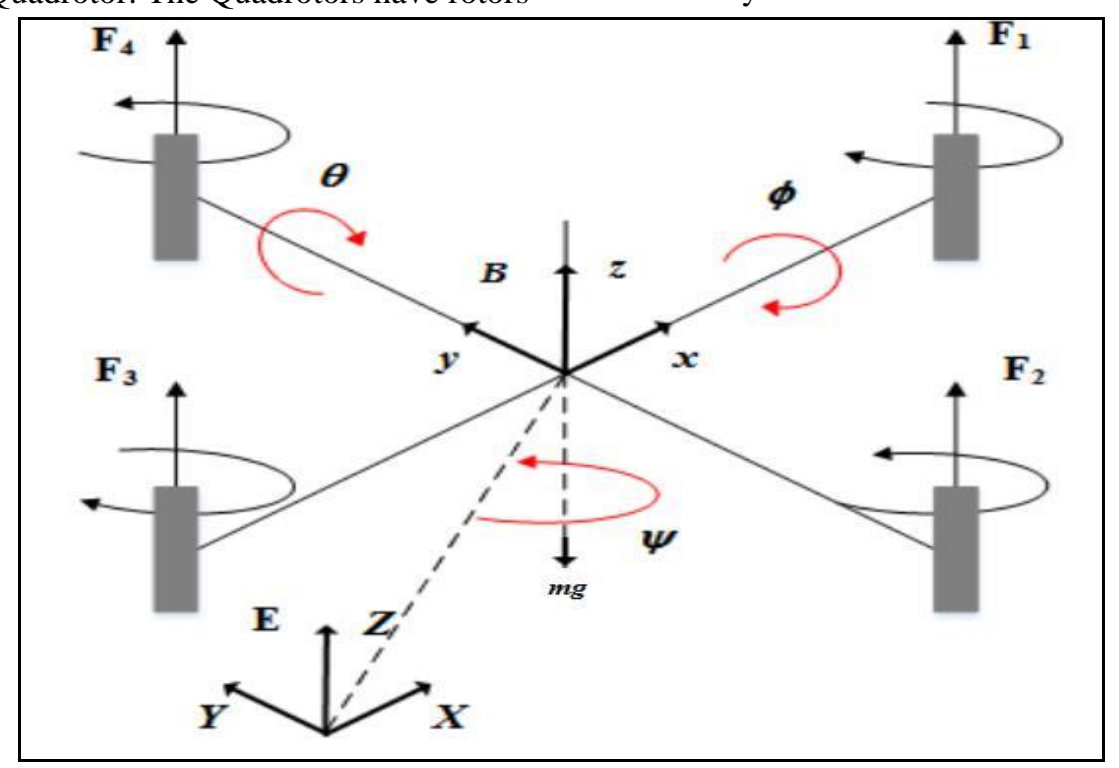

Figure 3. Schematic Diagram of a Quadrotor

Due to its simple design which offers great maneuverability, good control, and suitability to fly in any indoor and outdoor environment without any risk to human life; Quadrotors are extensively studied at Universities such as MIT and Stanford. The Mesicopter is a Quadrotor developed by Stanford[11].Companies like DJI, Draganflyer, Amazon, and Google are also developing cutting edge Quadrotors for applications ranging from surveying and mapping to product delivery. Most popular Quadrotor companies are Ascending technologies GmbH, Parrot SA, DJI.

\section{Different Modelling Techniques of Quadrotors}

There are two principles that are used for deriving the Quadrotor's model equations namely: $1^{\text {st }}$ principle of Approximation and Newton-Euler technique. The $1^{\text {st }}$ principle of Approximation includes Quaternion formulation and superposition formulation whereas Newton-Euler technique includes Newton-Euler and Euler-lagrange method. The models derived from Newton-Euler techniques are universally used because of its efficacy and can be categorized into three approaches as: angular-orientation approach, force-moment approach and voltage-based approach. The model equations obtained for the roll, pitch and yaw moment and the height, motion along $\mathrm{x}$ and $\mathrm{y}$ axes are listed in the table 3 .
The equations of motions or model equations described in table 3 are used to design a model of the Quadrotor in various simulation tools like MATLAB-Simulink, SciLab and LabVIEW. Position (x, y), Altitude (z) and Attitude $(\varphi, \theta, \psi)$ can be controlled using techniques. Roll Angle is denoted by $\varphi_{\text {(phi) angle. Pitch moment and yaw moment are }}$

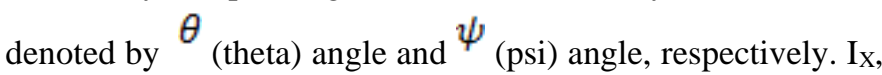
$\mathrm{I}_{Y}$ and $\mathrm{I}_{\mathrm{Z}}$ denotes the rotational inertia about $\mathrm{x}, \mathrm{y}$ and $\mathrm{z}$ axis. The mass of the Quadrotor is denoted by ' $\mathrm{m}$ ' whereas $F_{i}$ denotes force generated by four rotors of the Quadrotor.

Over the years, the researchers have made changes in the shape of the Quadrotors to achieve better models of the Quadrotors. Some of such approaches are described in the table 4, along with their advantages and features. The classical approach involves a symmetric frame in either ' $X$ ' or ' + ' configuration. This approach is widely used due to its simple design.

Table 3. Equations of motion using different approaches 


\begin{tabular}{|c|c|c|c|}
\hline & $\begin{array}{l}\text { Angular Orientation } \\
\text { Approach[12],[13] }\end{array}$ & $\begin{array}{l}\text { Force-Moment } \\
\text { Approach[14],[15] }\end{array}$ & Voltage-based Approach[16] \\
\hline $\begin{array}{l}\text { Roll } \\
\text { Mo } \\
\text { men } \\
\text { t }\end{array}$ & $\begin{array}{l}\ddot{\varphi}= \\
\dot{\theta} \dot{\psi}\left(\frac{I_{Y}-I_{Z}}{I_{X}}\right)-\frac{I_{R}}{I_{X}} \dot{\theta} \Omega+\end{array}$ & $\begin{array}{l}\ddot{\varphi}=\left(F_{1}-F_{2}-F_{3}+F_{4}\right. \\
\frac{l}{F} U_{2}\end{array}$ & $+\frac{k_{a}}{\varphi} \dot{\varphi} \frac{1}{L_{Y}}=\left[\left(2 \rho A d\left[\frac{\eta f K_{t}}{K_{a}}\right]^{2}\left(V_{2}{ }^{2}-V_{4}^{2}\right)\right)\right]$ \\
\hline $\begin{array}{l}\text { Pitc } \\
\text { h } \\
\text { Mo } \\
\text { men } \\
\text { t }\end{array}$ & $\begin{array}{l}\ddot{\theta}= \\
\dot{\varphi} \dot{\psi}\left(\frac{I_{Z}-I_{X}}{I_{Y}}\right)-\frac{I_{R}}{I_{Y}} \dot{\varphi} \Omega+\end{array}$ & $\begin{array}{l}\ddot{\theta}=\left(-F_{1}-F_{2}+F_{3}+F_{4}\right. \\
\frac{l}{I_{Y}} U_{3}\end{array}$ & 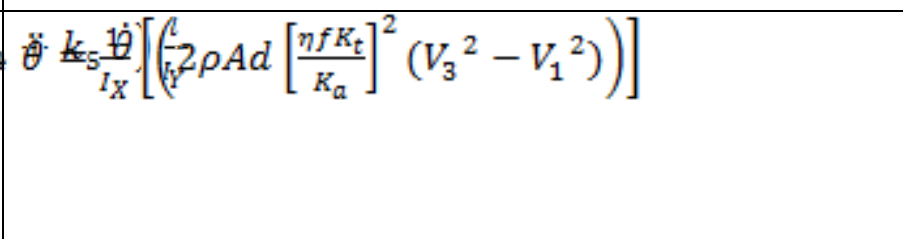 \\
\hline $\begin{array}{l}\text { Yaw } \\
\text { Mo } \\
\text { men } \\
\text { t }\end{array}$ & $\begin{array}{l}\ddot{\psi}_{=} \\
\dot{\varphi} \dot{\theta}\left(\frac{I_{X}-I_{Y}}{I_{Z}}\right)+\frac{1}{I_{Y}} U_{4}\end{array}$ & $\ddot{\psi}=\left(C F_{1}-C F_{2}+C F_{3}\right.$ & $\begin{array}{l}\left.-\ddot{\phi} F_{4} \frac{f}{f_{z z}} k\left(\Omega \Omega_{1}\right) H_{I_{Z}}^{l} \Omega_{3}^{y}-\Omega_{2}^{\prime}-\Omega_{4}^{y}\right)+D\left(\Omega_{1}^{2}+\Omega_{3}^{2}-\right. \\
\left.\Omega_{2}^{2}-\Omega_{4}^{2}\right)\end{array}$ \\
\hline $\begin{array}{l}\text { Heig } \\
\text { ht } \\
\text { (Mo } \\
\text { tion } \\
\text { alon } \\
\text { g Z- } \\
\text { axis) }\end{array}$ & $\ddot{Z}=-g+(\cos \varphi \cos \theta$ & 9) $\underset{m}{\frac{y_{1}}{2}}=\frac{1}{m} \sum_{1}^{4} F_{i}(\cos \varphi \cos \theta)$ & $\begin{array}{l}-\ddot{Z} \bar{g} \\
\frac{2 \rho A}{m}\left[\left[\frac{\eta f K_{\mathrm{t}}}{K_{a}}\right]^{2}\left(V_{1}^{2}+V_{2}^{2}+V_{3}^{2}+\right.\right. \\
\left.\left.V_{4}^{2}\right)\right](\cos \theta \cos \varphi)-g\end{array}$ \\
\hline $\begin{array}{l}\text { Mot } \\
\text { ion } \\
\text { alon } \\
\text { g X- } \\
\text { axis }\end{array}$ & $\ddot{X}=(\cos \varphi \sin \theta \cos \psi$ & 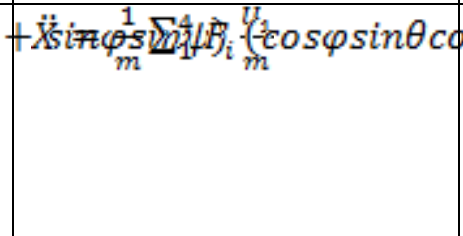 & 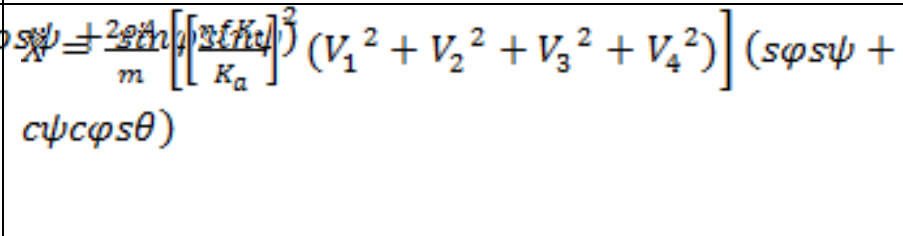 \\
\hline $\begin{array}{l}\text { Mot } \\
\text { ion } \\
\text { alon } \\
\text { g X- } \\
\text { axis }\end{array}$ & $\ddot{Y}=(\cos \varphi \sin \theta \sin \psi$ & 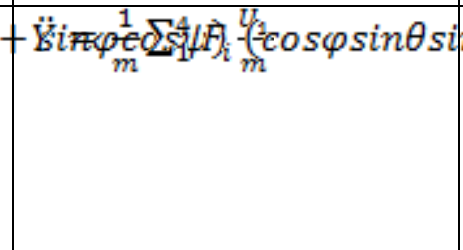 & $\begin{array}{l}n \ddot{\psi} \psi=\sin \varphi \cos \psi) \\
\frac{2 \rho A}{m}\left[\left[\frac{\eta f K_{\mathrm{t}}}{K_{a}}\right]^{2}\left(V_{1}^{2}+V_{2}^{2}+V_{3}^{2}+\right.\right. \\
\left.\left.V_{4}^{2}\right)\right](\sin \psi \sin \theta \cos \varphi-\cos \psi \sin \varphi)\end{array}$ \\
\hline
\end{tabular}

Technique

Classical Approach

Gyroscopic effect modeling
Table 4. Analysis of modifications made in modeling technique of a Quadrotor

\section{Advantage}

Remarks

Reference

Stability of equidistant rotors is Simple design achieved.

Stabilizes high RPM motors

Gyroscopic effect vanishes after the linearization of the system and this technique yields no added benefit. The design becomes complex. 
Use of different sized rotors

Design alteration of one rotor by 90 degrees
Different thrust disturbances and air drag is generated

Improves maneuverability and facilitates fast motion along one axis.
It violates the assumption that Quadrotors have a symmetric frame.

Additional controllers are required and design becomes complex.

\section{Control techniques used for Quadrotors}

Quadrotor system is stabilized to acquire desired values of various parameters like attitude i.e., roll, pitch, and yaw angle and translation motion (trajectory tracking) along $\mathrm{x}$ and $\mathrm{y}$ axis; and the altitude in $\mathrm{z}$-axis direction is obtained. The stabilization techniques that are used to actuate a Quadrotor are numerous like PID controller, Fuzzy controller, Adaptive controllers and Robust controllers. Proportional-IntegralDerivative (PID) shows good result for linear systems. The same controller might face some problem for non-linear system. Non-linear system can be stabilized by two methods: First, the system is linearized and then that system is controlled using a PID controller; the second method is using advanced controllers like fuzzy control, Fractional order PID, Neural control, Model Reference Adaptive control (MRAC) techniques.

Over the years, many control techniques have been used by the researchers to control the Quadrotors. Force moment approach based on Newton Euler technique was used to design a nonlinear control algorithm to stabilize the attitude and altitude of a Quadrotor vehicle. The nonlinear algorithm was based on the backstepping methodology integrated with the integral and adaptation schemes[21]. An intelligent fuzzy controller was designed using force moment approach[22] and the simulations results obtained were quite promising. However, the control technique had to compromise the precision and speed of the system response. Angular Orientation approach was used and the Quadrotor was commanded to change the orientation angles to zero and stabilize itself.

A PID controller cascaded with a proportional controller was used to stabilize the flight of an industrial Quadrotor. The accelerometers and gyroscope used in the Quadrotor, gathered data regarding its flight behavior and facilitated in the controlling of its attitude[23]. A PID and Linear Quadratic Regulator (LQR) are used to elucidate the trajectory tracking problem of Quanser Qball-X4. The reference trajectory was a circle of radius $0.5 \mathrm{~m}$. The trajectory obtained with LQR

Table 5, Control techniques used to control the Quadrotors

\section{Control action}

Proportional-Integral-Derivative (PID)

Model Reference Adaptive Control (MRAC) technique resulted in a more smooth trajectory with less disturbance[24].

A Quadrotor model was developed using voltage manipulation approach. The non-linear model obtained was linearized using Taylor-series first-order approximation and a PID control action was used to control the altitude of the Quadrotor. It was observed, as the system rises to greater heights, overshoots are recorded and the response time also increases[25].

A real-time trajectory tracking based on state feedback with integral action controller is designed for a Quadrotor system in NI-LabVIEW simulation software. The mission of the controller was to track a line, circle, ellipsoidal and figureeight path trajectory. The responses for $\mathrm{x}$ and $\mathrm{y}$ position and roll, pitch and yaw angles are recorded.

Adaptive Fuzzy control action was applied on a Quadrotor using Hardware-In-the-Loop (HIL) simulation in NILabVIEW software. The PID controller of the Quadrotor system was tuned using online Fuzzy tuner to enhance the PID controller to any new flight conditions and environmental factors. The desired height of the Quadrotor is achieved with more accuracy by adjusting the Fuzzy-PID to the Quadrotors behaviors. Some more control action techniques are listed in Table 5 . 
Fuzzy Control

[30]-[35]

Neural Network control

[36], [37]

Internal Model Controller (IMC)

[38], [39]

Model Predictive Controller (MPC)

[40]-[43]

Linear Quadratic Regulator (LQR)

Fractional order PID Controller

[45], [46]

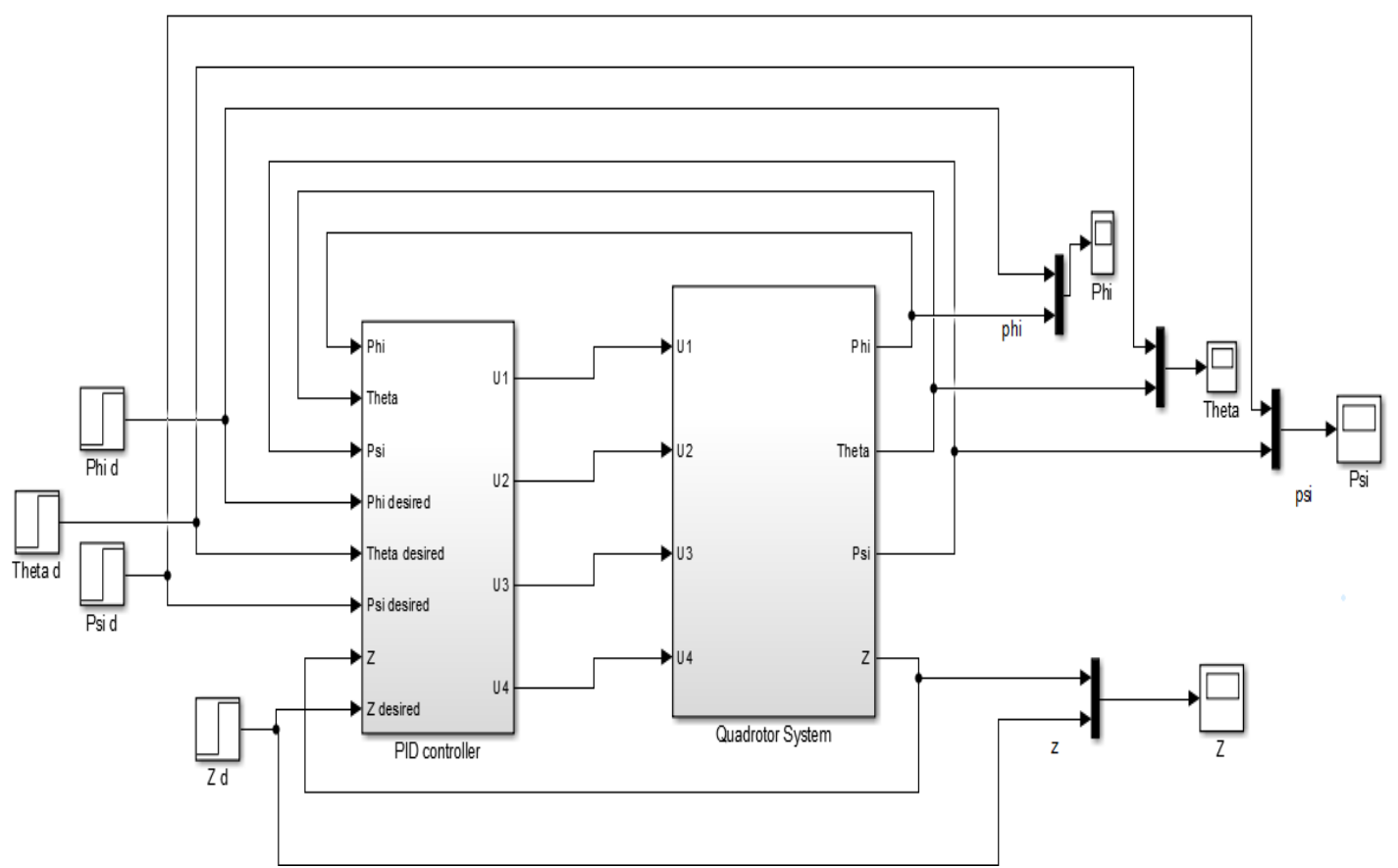

Figure 4. The model of Quadrotor system developed using Simulink

The mathematical equations obtained using force-moment approach (from Table 3) is used to develop a model in Simulink. The Simulink model is shown in Figure 4. The PID controller is used to control the attitude $(\varphi, \theta, \psi)$ and the altitude (motion along $\mathrm{z}$ axis) of the system and the results are shown in Figure 5.
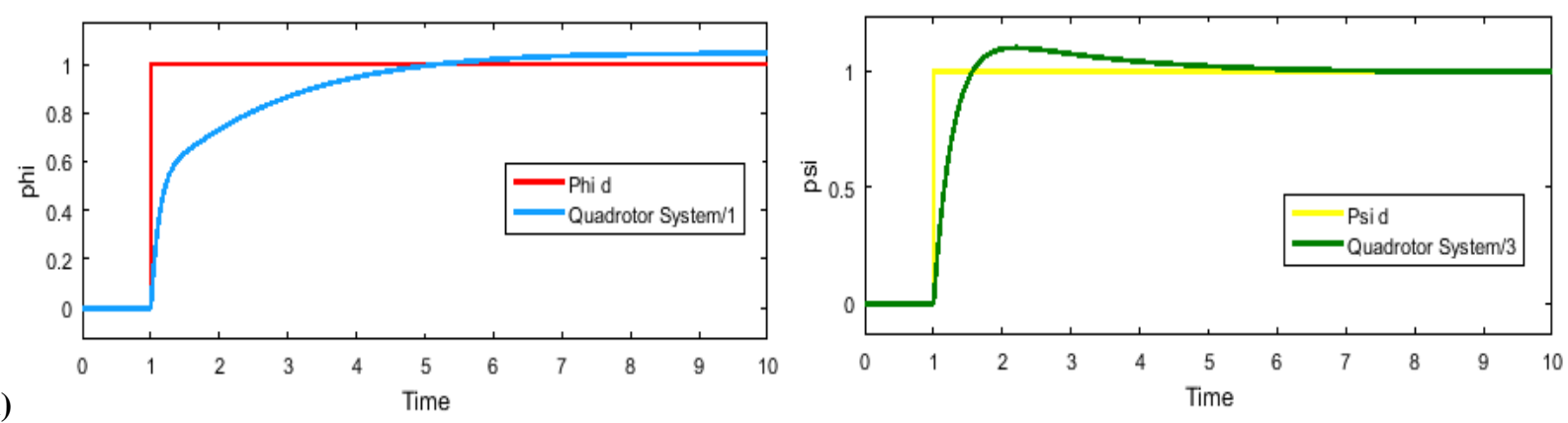

5(a)

5(b) 

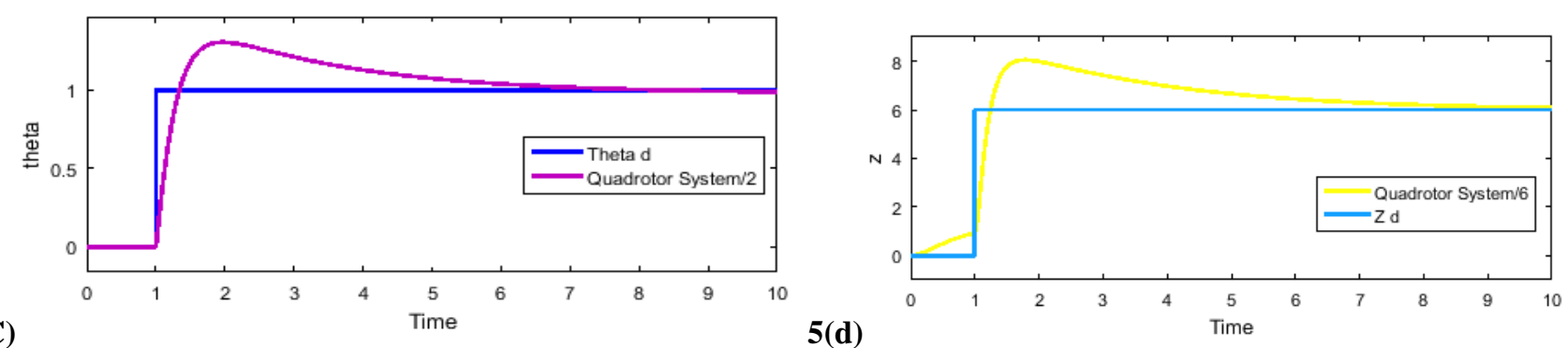

5(C)

$5(d)$

Figure 5(a) Response of Roll angle (phi) vs time, 5(b) Response of Yaw angle (psi) output vs time, 5(c) Response of Theta angle (pitch) output vs time and $\mathbf{5}(\mathbf{d})$ Response of motion along $\mathrm{z}$ axis output vs time

The model generated in Simulink using Force-moment differential equations in Table 3 and controlled using a PID controller is then used as a reference model to apply MRAC technique. Figure 6 shows the schematic of MRAC technique and the Simulink model is shown in figure 7. Figure 8 shows results of attitude $(\varphi, \theta, \psi)$ and altitude for MRAC technique. The response for roll angle and motion along $\mathrm{z}$ axis (altitude) are improved when MRAC is applied.

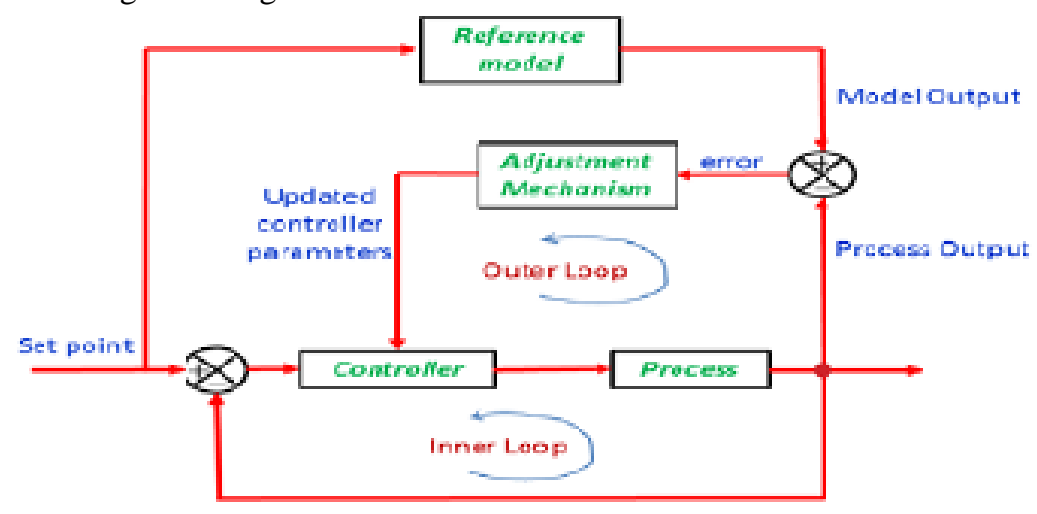

Figure 6. Schematic of MRAC technique

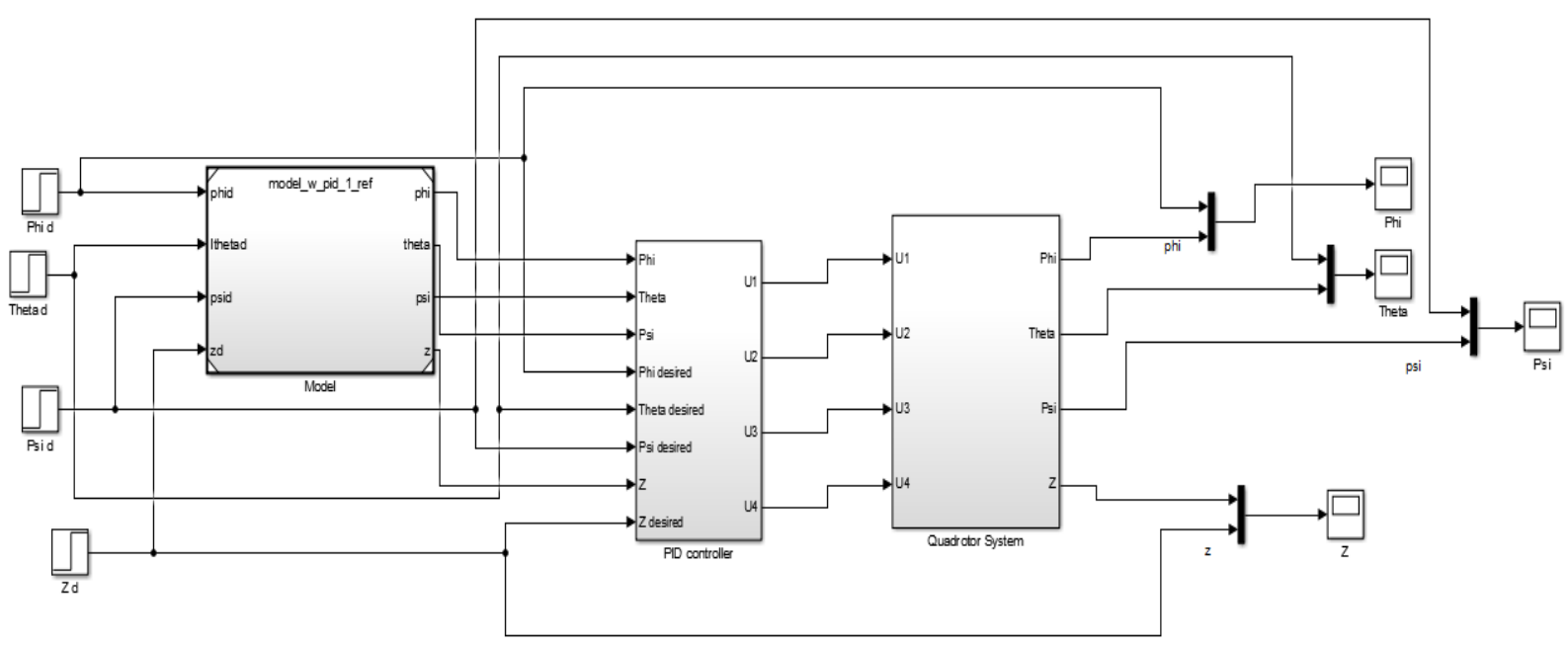

Figure 7. The model of Quadrotor system developed using Simulink for MRAC technique 


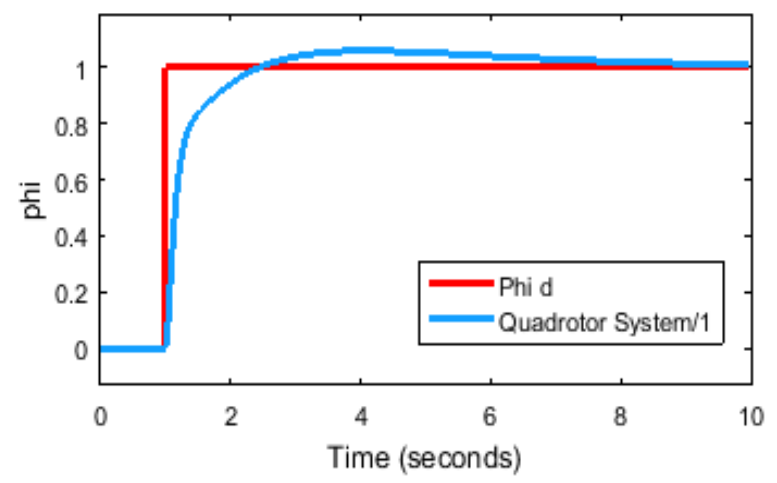

8(a)

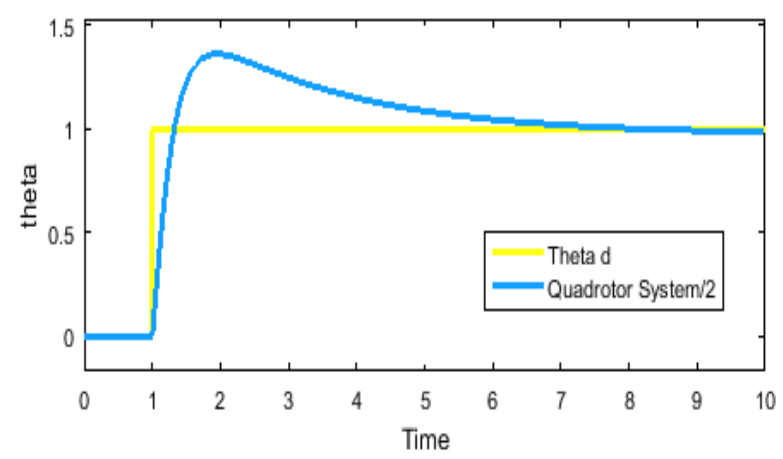

8(c)

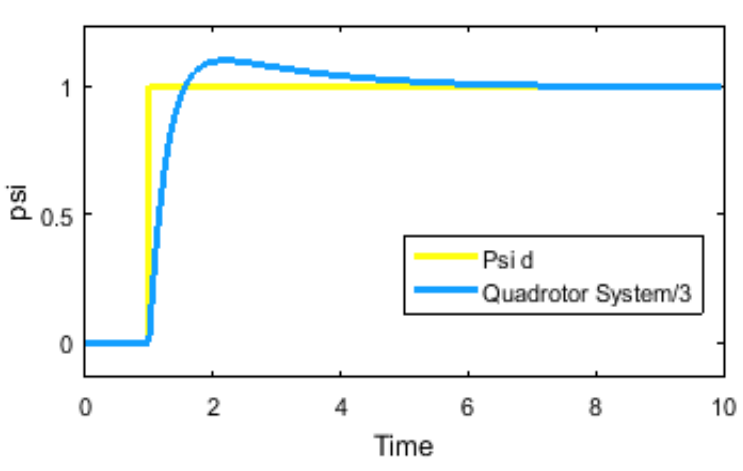

8(b)

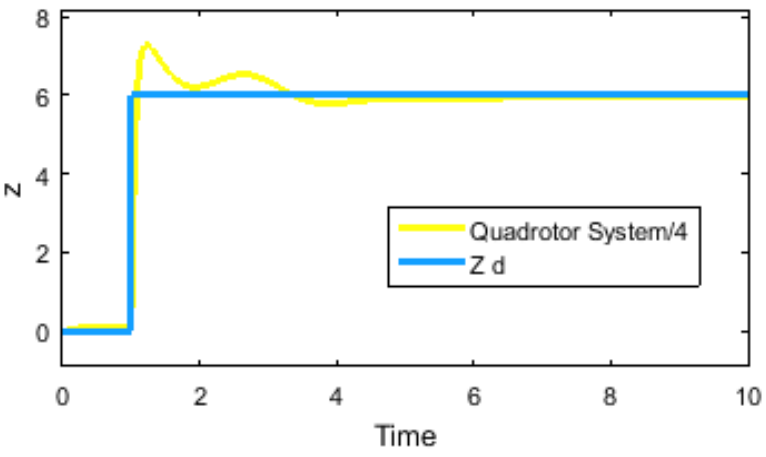

8(d)

Figure 8(a) Response of Roll angle (phi) vs time for MRAC Technique, 8(b) Response of Yaw angle (psi) output vs time for MRAC Technique, 8(c) Response of Theta angle (pitch) output vs time for MRAC Technique and 8(d) Response of motion along $\mathrm{z}$ axis output vs time for MRAC Technique

\section{Battery}

Demand for Quadrotor with high flight time is increasing for personal and commercial applications. The approximate time of flight for most Quadrotors is 30-40 minutes. Different types of batteries that are used are Lithium Ion (Li-ion) and Lithium Polymer (Li-Po) batteries. These Li-Po and Li-ion batteries are rechargeable. The light weight of these batteries makes them suitable for applications where weight plays a major role. For example, in product delivery applications the payload will add extra stress on the battery discharge as extra thrust would be required to take off the Quadrotor and stay in flight. Table 6, shows the comparison between Li-Po and Li-ion batteries.

Table 6. Comparison between Li-Po and Li-ion batteries

\begin{tabular}{|l|l|l|}
\hline Parameter & Li-ion Battery & Li-Po Battery \\
\hline Nominal Voltage & $3 \mathrm{~V}$ to $4.2 \mathrm{~V}$ & $3 \mathrm{~V}$ to $4.2 \mathrm{~V}$ \\
\hline Energy Density & High & Low and decreased cycle count \\
\hline Weight & Heavier & Light weight \\
\hline Cost & Cheaper & Costlier \\
\hline Capacity & Relatively low & Twice than Li-ion battery \\
\hline Rechargeable & True & True \\
\hline
\end{tabular}

Power Management is essential for a Quadrotor. There can be numerous components on board like GPS, Telemetry, Flight Controller, Electronic Speed Controllers (ESCs), Brushless DC motors and sensors like camera, barometer and pressure sensor. The number of these components used varies based on the real-life scenarios where they are deployed. An Intelligent
Battery Management System (IBMS) for Drones is proposed that uses Lithium ion battery with Lithium Titanite Oxide (LTO) anode as fast charging and fast discharging battery[47]. LTO have long lifetime, advanced safety and lower temperature performance than other Lithium batteries. LTO batteries can provide a nominal voltage of $48 \mathrm{~V}$. The IBMS proposed can increase the life of battery and its performance. 
The proposed system can accurately estimate the maximum available energy, so accurate flight time prediction can be done. This is a very crucial feature as this can prevent the Quadrotor from running out of power during its flight.

Solar Power can also be used to enhance the flight time of the Quadrotors. A light weight solar powered mini-Quadrotor is developed by modifying the model by adding a solar panel on top of the Quadrotor[48]. This is done to achieve optimal solar power. The model is focused on light weight applications that are centered on environment monitoring purposes. A fully solar powered Quadrotor is developed by team at National Taiwan University. The Quadrotor hardware models developed can take flight upto 3 hours and 28 minutes[49]. Two types of hardware are reported; 76 Solar cell based Quadrotor and 86 solar cell based Quadrotor model. The model developed is capable of receiving $100 \%$ of solar power.

\section{Applications of Quadrotors}

There is a diverse range of applications where a Quadrotor can be used. The low cost of manufacturing, availability of quality grade sensors and simplicity in its design have expanded the horizon of Quadrotors. Agriculture is one of the main areas where Quadrotors can be used. Other applications of the Quadrotor include Search and Rescue operations, remote sensing and geographical mapping, photogrammetry, product delivery and their use as communication relays. Applications such as indoor and outdoor mapping, target tracking, industrial inspection requires real-time estimation of UAV navigation states. They can be very beneficial in speculation of confined spaces and inaccessible areas which can prevent any calamity as the areas are under continuous supervision. The real-time data can alert the authorities about the slightest anomaly that might occur.

\section{Agriculture}

Agriculture is the dominant occupation in India. The constant increase in the requirement of the surplus food supplies due to increased population takes a toll on the crop health and food production. Environmental factors such as global warming, lead to an increase in the temperature which does not allow an ambient temperature to be maintained for the crops to grow. This leads to weed formation, droughts and bad quality of crops. Untimely rains due to global warming also destroy the crops and thus the production in the industries associated with agriculture gets affected. At the end of this chain, human lives get affected due to the scarcity of food resources, ill quality food available in the market.

Quadrotors can a vital role to overcome these difficulties. They can be used in Precision Agriculture for the management of crops, scheduling the irrigation of crops, health and disease diagnosis, insecticide spraying and collecting sensor data installed in the field to detect soil moisture, temperature and soil properties. The advancement in wireless communication technology like the use of MQTT protocols, 6LowPan and LoRa will help the Quadrotors to better assist the farmers by transmitting real-time data to the base station. The data collected in real-time will also allow the farmers to analyze which type of crop should be planted in the next season to maintain and preserve the fertility of the soil. This will also aid the farmers to avoid any unnecessary trips to the field to inspect the crops. This ensures that there is no wastage of resources due to over-irrigation and over insecticide spraying in the fields. Food and Agricultural Organization (FAO) of the United Nations believes there is potential to increase crop yields, with technology playing a major role in helping to boost production efficiency[50]. Quadrotors can cover large areas in a comparably short amount of time and do not impact the fields through soil compaction as ground vehicles do[51]. Table 7, describes the work done in the field of agriculture on Quadrotors.

Table 7.Description of work done in the field of agriculture using Quadrotor

\begin{tabular}{|l|l|l|}
\hline Quadrotor & Features & Reference \\
\hline $\begin{array}{l}\text { UREA spraying } \\
\text { Quadrotor }\end{array}$ & -Low power consumption & {$[52]$} \\
& -30 minutes of Endurance & \\
\hline Agridrone & -Payload capacity of 5.5 kg & \\
& -Raspberry Pi is connected with Wifi module & \\
& $\begin{array}{l}\text {-The captured images are stored in SD cards and } \\
\text { are processed using OpenCV }\end{array}$ & \\
\hline AR.Drone 2.0 & -Commercially available Quadrotor & {$[54]$} \\
\hline
\end{tabular}




\begin{tabular}{|c|c|c|}
\hline & $\begin{array}{l}\text {-Can be used to determine that a trailer is filled } \\
\text { with crops evenly } \\
\text {-Image data helps remove the fisheye effect which } \\
\text { occurs when a human being is supervising. } \\
\text {-This helps to map the volume of grains during } \\
\text { harvesting season }\end{array}$ & \\
\hline $\begin{array}{l}\text { Robust Quadrotor for } \\
\text { agricultural surveillance }\end{array}$ & $\begin{array}{l}\text {-IR light radiation is used to obtain images of } \\
\text { agricultural crop areas. } \\
\text {-Determines the tentative position of unhealthy } \\
\text { crops } \\
\text {-Corrective measures can be applied at the } \\
\text { affected positions at the earliest. }\end{array}$ & {$[55]$} \\
\hline
\end{tabular}

\section{Product Delivery}

Transportation drones that are competent in taking off and landing in the vicinity of buildings and humans will enable the developing countries, deprived of proper road connectivity, to swiftly deliver goods. This would unleash the full capability of their product delivery infrastructure. Developed countries will be able to improve the quality of service in congested or remote areas and will empower rescue organizations to quickly deliver medical supplies in the field.

The evolution of e-commerce with the advent of internet has been magnificent but high demand for fast delivery might pose a problem for e-commerce companies in the near future. Product delivery using Quadrotors within an area can ease the pressure on the product delivery system. The drone delivery market will thrive on factors such as the regulatory framework of various countries and low-cost associated with product delivery by Quadrotors. Based on fight duration, the Quadrotor based product delivery market has been segmented into short duration and long duration segments. The short duration ( $<30$ minutes) segment is estimated to account for a larger share of the overall market in 2023. However, the long duration segment (> 30 minutes) is projected to grow at a higher rate during the forecast period owing to the demand for instant package delivery at a lower cost. The market has also been segmented based on their coverage area, into short-range $(<5 \mathrm{~km})$ and long-range $(>25$ kilometers). Short-range delivery drones are largely used for a short-range local delivery of packages. These drones are capable of traveling up to a distance of 25 kilometers in a single charging; enable instantaneous delivery of products after their online purchase. There is a rising demand for instant delivery of products and packages, such as medicines and food. It is expected that Asia-Pacific will lead the drone package delivery market in 2023.
China and Japan are the major countries in the Asia Pacific drone package delivery market and are leaders in the manufacturing of advanced delivery drones for commercial usage. Australia is among the most lucrative markets in the Asia Pacific Region. Alphabet's Wing has started the delivery of packages using drones in Australian suburbs in April 2019. Amazon Prime is also conducting trials for the delivery of parcels through drones within thirty minutes[56]. The drone logistics and transportation market is estimated to be valued at USD 11.20 Billion in 2022 and is projected to reach USD 29.06 Billion by 2027 , at a CAGR of $21.01 \%$.

Environmental pollution caused by the logistics and transportation industry can be reduced by using UAVs that is why; companies like Amazon, Google, UPS, and Deutsche Post DHL are producing product delivery Quadrotors. Israeli startup Flytrex has been trialing its drone logistics service in Iceland from 2017 and Flirtey has been making commercial drones for 7-Eleven in the US back as early as 2016. UPS partnered with Matternet is expected to experiment with drones to deliver supplies in North Carolina[57]. Some of them have even registered for patents[58]. A brief description regarding some of these companies that are working on product delivery drones is discussed below:

\section{Amazon Prime Air}

Amazon has been working on a fully autonomous delivery system using drones called the Amazon Prime Air. The products will be delivered within 30 minutes of ordering them. This rapid delivery system is set to increase the overall safety and efficiency of the transportation system[56]. The products delivered can weigh up to 5 pounds $(2.26 \mathrm{Kg})$. Many designs and delivery mechanisms are being tested to figure out the best suitable design for the product delivery. They have established their development centers in the US, the UK, Austria, France, and Israel. 


\section{Sony's VTOL}

Sony has been working on a Vertical Take-Off and Landing (VTOL) along with ZMP Incorporation. The drone is expected to carry a payload of 22 pounds $(9.97 \mathrm{Kg})$. The expected flight time is 2 hours with a speed of $100 \mathrm{mph}[59]$.

\section{Google}

Australian aviation authority (Casa) approved the Alphabet's Project Wing to deliver food and drinks, medication and locally made coffee and chocolate [57]. Alphabet is an offshoot of Google and it took them 18 months to obtain regulatory approval. These drones are banned from crossing over major roads, and there is a minimum distance they have to maintain from people on the ground. This would help in the reduction of delivery cost as well as reduction in the carbon emissions. It is estimated that the drones will deliver more than one in four takeaway food orders and up to 4-6\% of all purchases by 2030. Product delivery options are being explored in the United Kingdom also[60].

Table 8, lists the various Quadrotors developed by major companies like Sony and Amazon, and their payload capacity.

Table 8, Quadrotor and their payload capacity

\begin{tabular}{|l|l|l|}
\hline S.no. & Quadrotor name & $\begin{array}{l}\text { Payload capacity } \\
\text { (in Kg) }\end{array}$ \\
\hline 1. & 3D Robotics' Iris & 0.5 \\
\hline 2. & Turbo Ace's Infinity 9 & 8.1 \\
\hline 3. & Sony's VTOL & 9.97 \\
\hline 4. & Amazon's Prime Air & 2.26 \\
\hline
\end{tabular}

One of the major real-time applications of Quadrotor delivery can be the delivery of medicines in areas struck by natural calamities like floods and earthquakes. Presently, the world is fighting a highly contagious virus and social distancing protocols need to be ensured to stop the spread of the virus (COVID-19). Quadrotor can used to send medicines in containment zones. This would help maintain zero human contact with human beings.

\section{Results and discussion}

UAVs can play a vital role in the implementation of various real-time scenarios like product and medicine delivery, and agriculture. Simplistic design, robust maneuverability and ability to hover; makes the Quadrotors ideal for their services in areas like product delivery and inspection of crops. With the advent of technological advancement in communication technologies like 5G, internet connectivity will increase manifold. Physical devices will be able to obtain data via sensors and send this live data over the internet to the base station. Quadrotors installed with various sensors like high spectral cameras would be able to send data over the internet for real-time processing. The can help with the implementation of Smart and connected cities.

\section{Conclusion}

In this paper, a comprehensive survey of UAVs is presented. It highlighted the market share possessed by the UAVs their various types. Further emphasis has been given on the study of Quadrotors. The different types of batteries used to power the Quadrotor and applications of Quadrotors have been studied in brief. The various modeling and control techniques have been discussed. Controlling techniques like LQR, LQG, PID and robust control are implemented for position, attitude and altitude control. Results for Proportional Integral and Derivative (PID) and Model Reference Adaptive Control (MRAC) of model generated using force-moment mathematical model are implemented, analyzed and compared using MATLAB Simulink. These control techniques are implemented for position, attitude and altitude control. In this paper, it has been concluded that MRAC performs better as compared to PID controller for position, attitude and Altitude control of Quadrotor.

\section{References:}

[1]. Y. Ham, K. K. Han, J. J. Lin, and M. GolparvarFard, "Visual monitoring of civil infrastructure systems via camera-equipped Unmanned Aerial Vehicles (UAVs): a review of related works," Visualization in Engineering, vol. 4, no. 1. Springer, p. 1, Dec. 06, 2016, doi: 10.1186/s40327015-0029-z.

[2]. A. A. Najm and I. K. Ibraheem, "Nonlinear PID controller design for a 6-DOF UAV quadrotor system,” Eng. Sci. Technol. an Int. J., vol. 22, no. 4, pp. 1087-1097, Aug. 2019, doi: 10.1016/j.jestch.2019.02.005.

[3]. K. Herrick, "Development of the unmanned aerial vehicle market: forecasts and trends," Air Sp. Eur., vol. 2, no. 2, pp. 25-27, 2000, doi: 10.1016/s12900958(00)80035-0.

[4]. "Drone market worth \$127bn - Supply Management." https:/www.cips.org/en-SG/supplymanagement/news/2018/may/drone-market-worth127bn/ (accessed Feb. 17, 2020).

[5]. "Commercial Drones Market 2019: Worldwide Industry Overview, Supply Demand and Shortage, Trends, Demand, Overview, Forecast 2025 MarketWatch."

https://www.marketwatch.com/pressrelease/commercial-drones-market-2019worldwide-industry-overview-supply-demand-andshortage-trends-demand-overview-forecast-20252019-12-02 (accessed Feb. 17, 2020). 
[6]. H. Shakhatreh et al., "Unmanned Aerial Vehicles (UAVs): A Survey on Civil Applications and Key Research Challenges," IEEE Access, vol. 7, pp. 48572-48634, 2019, doi: 10.1109/ACCESS.2019.2909530.

[7]. "The Drone Market and Industry Trends | Toptal." https://www.toptal.com/finance/market-researchanalysts/drone-market (accessed Mar. 14, 2020).

[8]. J. Xiao, "Trajectory planning of quadrotor using sliding mode control with extended state observer," Meas. Control (United Kingdom), p. 002029402092741, Jun. 2020, doi: 10.1177/0020294020927419.

[9]. T. Hamel and R. Mahony, "Attitude estimation on SO (3) based on direct inertial measurements," Proc. - IEEE Int. Conf. Robot. Autom., vol. 2006, no. May, pp. 2170-2175, 2006, doi: 10.1109/ROBOT.2006.1642025.

[10]. S. Bouabdallah, A. Noth, and R. Siegwart, "PID vs LQ control techniques applied to an indoor micro quadrotor,” 2004 IEEE/RSJ Int. Conf. Intell. Robot. Syst. (IEEE Cat. No.04CH37566), vol. 3, no. March 2014, pp. 2451-2456, 2004, doi: 10.1109/IROS.2004.1389776.

[11]. I. Kroo, F. Prinz, M. Shantz, and P. Kunz, "The Mesicopter: a miniature rotorcraft concept-phase ii interim report," pp. 1-47, 2000, [Online]. Available:

http://adg.stanford.edu/mesicopter/progressreports/ mesicopterinterimreport.pdf.

[12]. E. Abbasi and M. Mahjoob, "Controlling of Quadrotor UAV Using a Fuzzy System for Tuning the PID Gains in Hovering Mode," 10th Int. Conf. Adv. Comput. Entertain. Technol., no. September 2013, pp. 1-6, 2013, [Online]. Available: http://conf-scoop.org/ACE-

2013/13_Reza2_ACE.pdf.

[13]. A. Zulu and S. John, "A Review of Control Algorithms for Autonomous Quadrotors," Open J. Appl. Sci., vol. 04, no. 14, pp. 547-556, Feb. 2014, doi: 10.4236/ojapps.2014.414053.

[14]. C. Cömert and C. Kasnakoglu, "Comparing and Developing PID and sliding mode Controllers for Quadrotor,” Int. J. Mech. Eng. Robot. Res., 2017, doi: 10.18178/ijmerr.6.3.194-199.

[15]. D. Gautam and C. Ha, "Control of a quadrotor using a smart self-tuning fuzzy PID controller," Int. J. Adv. Robot. Syst., 2013, doi: 10.5772/56911.

[16]. A. Bousbaine, M. H. Wu, and G. T. Poyi, "Modelling and simulation of a quad-rotor helicopter," in IET Conference Publications, 2012, vol. 2012, no. 592 CP, doi: 10.1049/cp.2012.0318.
[17]. T. N. Dief, "Modeling and Classical Controller of Quad-rotor," vol. 5, no. August, pp. 314-319, 2015.

[18]. K. S. Kim and Y. Kim, "Robust backstepping control for slew maneuver using nonlinear tracking function," IEEE Trans. Control Syst. Technol., vol. 11, no. 6, pp. 822-829, Nov. 2003, doi: 10.1109/TCST.2003.815608.

[19]. S. H. Jeong and S. Jung, "A quad-rotor system for driving and flying missions by tilting mechanism of rotors: From design to control," in Mechatronics, Dec. 2014, vol. 24, no. 8, pp. 1178-1188, doi: 10.1016/j.mechatronics.2014.09.006.

[20]. P. Getsov, S. Zabunov, and G. Mardirossian, "Quad-Rotor Unmanned Helicopter Designs," Asian J. Nat. Appl. Sci., vol. 3, no. September, pp. 77-82, 2014.

[21]. Y. M. Al-Younes, M. A. Al-Jarrah, and A. A. Jhemi, "Linear vs. nonlinear control techniques for a quadrotor vehicle," Mechatronics its Appl. (ISMA), 2010 7th Int. Symp., pp. 1-10, 2010, doi: 10.1186/1471-2458-14-647.

[22]. M. Santos, V. López, and F. Morata, "Intelligent fuzzy controller of a quadrotor," Proc. 2010 IEEE Int. Conf. Intell. Syst. Knowl. Eng. ISKE 2010, pp. 141-146, 2010, doi: 10.1109/ISKE.2010.5680812.

[23]. P. Burggräf, A. R. Pérez Martínez, H. Roth, and J. Wagner, "Quadrotors in factory applications: design and implementation of the quadrotor's P-PID cascade control system," SN Appl. Sci., vol. 1, no. 7, pp. 1-17, 2019, doi: 10.1007/s42452-019-06987.

[24]. C. Liu, J. Pan, and Y. Chang, "PID and LQR trajectory tracking control for an unmanned quadrotor helicopter: Experimental studies," Chinese Control Conf. CCC, vol. 2016-Augus, pp. 10845-10850, 2016, doi: 10.1109/ChiCC.2016.7555074.

[25]. S. Musa, "Techniques for Quadcopter Modelling \& Design:A review," no. May, 2018, doi: 10.21535/just.v5i3.981.

[26]. S. Khatoon, M. Shahid, Ibraheem, and $\mathrm{H}$. Chaudhary, "Dynamic modeling and stabilization of quadrotor using PID controller," Proc. 2014 Int. Conf. Adv. Comput. Commun. Informatics, ICACCI 2014, pp. 746-750, 2014, doi: 10.1109/ICACCI.2014.6968383.

[27]. N. Bao, X. Ran, Z. Wu, Y. Xue, and K. Wang, "Research on attitude controller of quadcopter based on cascade PID control algorithm," Proc. 2017 IEEE 2nd Inf. Technol. Networking, Electron. Autom. Control Conf. ITNEC 2017, vol. 2018Janua, pp. 1493-1497, 2018, doi: 10.1109/ITNEC.2017.8285044. 
[28]. Y. Zeng, Q. Jiang, Q. Liu, and H. Jing, "PID vs. MRAC control techniques applied to a Quadrotor's attitude," 2012, doi: 10.1109/IMCCC.2012.256.

[29]. B. T. Whitehead and S. R. Bieniawskiy, "Model Reference Adaptive Control of a quadrotor UAV," 2010, doi: 10.2514/6.2010-8148.

[30]. K. Boudjit and C. Larbes, "Detection and target tracking with a quadrotor using fuzzy logic," Proc. 2016 8th Int. Conf. Model. Identif. Control. ICMIC 2016, pp. 127-132, 2017, doi: 10.1109/ICMIC.2016.7804285.

[31]. V. S. Fnu and K. Cohen, "Intelligent Fuzzy Flight Control of an Autonomous," no. January, 2014, doi: 10.2514/6.2014-0992.

[32]. N. M. Raharja, E. Firmansyah, A. I. Cahyadi, and Iswanto, "Hovering control of quadrotor based on fuzzy logic," Int. J. Power Electron. Drive Syst., vol. 8, no. 1, pp. 492-504, 2017, doi: 10.11591/ijpeds.v8i1.pp492-504.

[33]. A. S. Kumar, M. S. Rao, and Y. S. K. Babu, "Model reference linear adaptive control of DC motor using fuzzy controller," 2008, doi: 10.1109/TENCON.2008.4766484.

[34]. B. E. Demir, R. Bayir, and F. Duran, "Real-time trajectory tracking of an unmanned aerial vehicle using a self-tuning fuzzy proportional integral derivative controller," doi: 10.1177/1756829316675882.

[35]. J. Ma and R. Ji, "Fuzzy PID for quadrotor space fixed-point position control," Proc. - 2016 6th Int. Conf. Instrum. Meas. Comput. Commun. Control. IMCCC 2016, pp. 721-726, 2016, doi: 10.1109/IMCCC.2016.131.

[36]. S. Bansal, A. K. Akametalu, F. J. Jiang, F. Laine, and C. J. Tomlin, "Learning quadrotor dynamics using neural network for flight control," 2016, doi: 10.1109/CDC.2016.7798978.

[37]. T. Dierks and S. Jagannathan, "Neural network control of quadrotor UAV formations," in Proceedings of the American Control Conference, 2009, pp. 2990-2996, doi: 10.1109/ACC.2009.5160591.

[38]. Q. Gao, M. Du, and Y. Ji, "The controller design of quadrotor UAV based on internal model control," 2017, doi: 10.23919/ChiCC.2017.8027393.

[39]. Z. He and L. Zhao, "Internal model control /backstepping sliding model control for quadrotor trajectory tracking," 2018, doi: 10.1109/ITNEC.2017.8284977.

[40]. P. Bouffard, A. Aswani, and C. Tomlin, "Learningbased model predictive control on a quadrotor: Onboard implementation and experimental results," 2012, doi: 10.1109/ICRA.2012.6225035.
[41]. K. Alexis, G. Nikolakopoulos, and A. Tzes, "Switching model predictive attitude control for a quadrotor helicopter subject to atmospheric disturbances," Control Eng. Pract., vol. 19, no. 10, pp. 1195-1207, 2011, doi: 10.1016/j.conengprac.2011.06.010.

[42]. A. Tzes, G. Nikolakopoulos, and K. Alexis, "Model predictive quadrotor control: attitude, altitude and position experimental studies," IET Control Theory Appl., vol. 6, no. 12, pp. 1812-1827, 2012, doi: 10.1049/iet-cta.2011.0348.

[43]. K. Alexis, C. Papachristos, G. Nikolakopoulos, and A. Tzes, "Model predictive quadrotor indoor position control," 2011, doi 10.1109/MED.2011.5983144.

[44]. F. Rinaldi, S. Chiesa, and F. Quagliotti, "Linear quadratic control for quadrotors UAVs dynamics and formation flight," J. Intell. Robot. Syst. Theory Appl., vol. 70, no. 1-4, pp. 203-220, 2013, doi: 10.1007/s10846-012-9708-3.

[45]. J. Han, L. Di, C. Coopmans, and Y. Chen, "Pitch loop control of a VTOL UAV using fractional order controller," J. Intell. Robot. Syst. Theory Appl., vol. 73, no. 1-4, pp. 187-195, 2014, doi: 10.1007/s10846-013-9912-9.

[46]. H. Senberber and A. Bagis, "Fractional PID controller design for fractional order systems using ABC algorithm," Proc. 21st Int. Conf. Electron., vol. 6, pp. 4-10, 2017, doi: 10.1109/ELECTRONICS.2017.7995218.

[47]. S. R. Hashemi et al., "New intelligent battery management system for drones," ASME Int. Mech. Eng. Congr. Expo. Proc., vol. 6, pp. 1-7, 2019, doi: 10.1115/IMECE2019-10479.

[48]. "A Light Weight Solar Powered Mini Quadcopter.pdf.".

[49]. C. F. Lin et al., "Solar Power Can Substantially Prolong Maximum Achievable Airtime of Quadcopter Drones," Advanced Science, vol. 7, no. 20. 2020, doi: 10.1002/advs.202001497.

[50]. A. Hunter, "The effect of population growth on efficiency in food production," Food Beverage, vol. 108, no. April, pp. 95-96, 2016, Accessed: Dec. 13, 2019. [Online]. Available: https://www.potatopro.com/news/2016/effectpopulation-growth-efficiency-food-production.

[51]. P. Lottes, R. Khanna, J. Pfierfer, C. Stachniss, and R. Siegwart, "UAV-based crop and weed classification for future farming," Robohub, pp. 3024-3031, 2017, [Online]. Available: https://robohub.org/uav-based-crop-and-weedclassification-for-future-farming/. 
[52]. S. Meivel, K. Dinakaran, N. Gandhiraj, and M. Srinivasan, "Remote sensing for UREA Spraying Agricultural (UAV) system," in ICACCS 2016 3rd International Conference on Advanced Computing and Communication Systems: Bringing to the Table, Futuristic Technologies from Arround the Globe, 2016, no. January 2016, doi: 10.1109/ICACCS.2016.7586367.

[53]. S. Nandyal, P. Khamitkar, U. Student, and P. Joshi, "Agridrone: Automation of Agriculture using IoT," Ijisrt.Com, vol. 4, no. 6, pp. 75-79, 2019, [Online]. Available: https://ijisrt.com/wpcontent/uploads/2019/06/IJISRT19JU84.pdf.

[54]. A. Hernandez, H. Murcia, C. Copot, and R. De Keyser, "Towards the development of a smart flying sensor: Illustration in the field of precision agriculture," Sensors (Switzerland), vol. 15, no. 7, pp. 16688-16709, 2015, doi: 10.3390/s150716688.

[55]. P. N. Patel, M. A. Patel, R. M. Faldu, and Y. R. Dave, "Quadcopter for Agricultural Surveillance," Adv. Electron. Electr. Eng., vol. 3, no. 4, pp. 427432, 2013, [Online]. Available: http://www.ripublication.com/aeee.htm\%5Cnhttp:// www.ripublication.com/aeee/55_pp 427-432.pdf.

[56]. "Amazon.com: Prime Air." https://www.amazon.com/Amazon-PrimeAir/b?ie $=$ UTF8\&node $=8037720011$ (accessed Jan . 29, 2020).

[57]. “Google's world-first drone delivery business wins approval in Canberra | Australia news | The Guardian." https://www.theguardian.com/australianews/2019/apr/09/googles-world-first-dronedelivery-business-wins-approval-in-canberra (accessed Jan. 31, 2020).

[58]. J. K. Stolaroff, C. Samaras, E. R. O’Neill, A. Lubers, A. S. Mitchell, and D. Ceperley, "Energy use and life cycle greenhouse gas emissions of drones for commercial package delivery," Nat. Commun., vol. 9, no. 1, pp. 1-13, 2018, doi: 10.1038/s41467-017-02411-5.

[59]. “Sony's New Drone Is A Helicopter In A Plane's Body | Popular Science." https://www.popsci.com/sonys-new-dronehelicopter-planes-body/ (accessed Jan. 28, 2020).

[60]. "Google's sister company Wing exploring UK drone delivery push." https://www.telegraph.co.uk/technology/2020/01/11 /googles-sister-company-wing-exploring-uk-dronedelivery-push/ (accessed Jan. 31, 2020). 